\title{
Prolapse of colostomy in children; characteristics, predisposing factors and preventive measures in four health facilities in Southern Nigeria
}

\author{
Okoro Philemon $\mathrm{E}^{1 *}$, Onyesoh Chinyeaka ${ }^{2}$
}

${ }^{1}$ Paediatric Surgery Unit, Department of Surgery, University of Port Harcourt Teaching Hospital, Port Harcourt, Rivers State Nigeria and Department of Surgery, Madonna University Teaching Hospital, Elele Rivers State, Nigeria and Paediatrics Unit, St Catherine's Specialist Hospital Ltd and Citihome Medical Consultants Ltd, Port Harcourt, Nigeria

${ }^{2}$ Paediatrics Unit, St Catherine’s Specialist Hospital Ltd

DOI: https://doi.org/10.15520/ijmhs.v9i5.2595

Accepted 15 May 2019; Received 01 May 2019; Published Online 5 Jun 2019

Reviewed By: Dr

Daniel V.

Department: Medical

\begin{abstract}
Introduction

The protrusion of the bowel through the stoma in a colostomy is one of the common complications of colostomy. Though it rarely gets secondarily complicated, it causes significant morbidity by virtue of the increasing bowel mass outside. The predisposing factors and progression in children are not well reported in our region.
\end{abstract}

Aim

To evaluate the characteristics and occurrence of colostomy prolapse in children and to identify any factors predisposing to this complication in our practice.

\section{Patients and Methods}

This is a five year prospective study of paediatric colostomy in the authors' service between March 2013 and April 2018. Patients were categorized into those that developed prolapse (Pro group), and those that did not (Non Pro group). Other variables investigated were gender, age at creation of colostomy, indication, type, and duration of colostomy, presence of raised intra abdominal pressure. Statistics was with SPSS 21.

\section{Results}

Twenty seven (28.4\%) of 95 children who had colostomy during the study period developed prolapsed. Prolapse occurred more in patients who had their colostomy at a relatively older age. There was a positive association of prolapse and Hirschsprungs disease but no association with the gender or duration of stoma. Conclusion

Colostomy prolapse is a common complication seen in our practice. Cases of neglected Hirschsprungs disease in children have increased risk of this complication. Extra caution is therefore needed in forming colostomy in this group of patients.

Keywords: Colostomy; Prolapse; Paediatric; Risk factors; Morbidity; Prevention

\footnotetext{
${ }^{\star}$ Corresponding author.

† Email: philemon.okoro@uniport.edu.ng.
} 


\section{INTRODUCTION}

Colostomy is a common colonic stoma created to divert faeces away from the distal colonic segment and is often needed as an emergency and sometimes elective procedure in children., Fashioning of colostomy irrespective of the type, aims at creating a stoma which will be a hillock of $1-3 \mathrm{~cm}$ above the skin level to enable easy application of colostomy bags and collection of effluence. ${ }^{3,4}$ Sometimes, the hillock begins to protrude further constituting a mass of bowel (colostomy prolapse) which is unsightly, makes use of appliances difficult and may predispose to skin excoriations. Prolapse of the colostomy is one of the common

complications of colostomy reported worldwide. ${ }^{5,6,7}$ Of all the reported complications, it represents the most unsightly and often difficult to care for. It is recognized to constitute significant morbidity in patients who had colostomy. Apart from the social and psychological burden of lowered self esteem, and extra care required to manage it, it is sometimes associated with dragging sensation, pain and may be further complicated with bleeding, ulceration or occasionally obstruction, or accidental rupture. These secondary complications are uncommon and consequently, colostomy prolapse is mostly managed conservatively. ${ }^{8,9,10}$ This is even more so in children where the vast majority are temporary colostomies. This line of practice therefore, leaves the child to cope with the discomfort of dragging around such protuberant bowel loop for lengthy periods. The reasons patients with colostomy develop prolapse are not always obvious but they may be related to the size of the defect through which the stoma was made, presence of raised intra abdominal pressure, dilated bowel loop and the type of suture material used in securing the stoma. However, there is no report to establish a cause effect relationship regarding these stated predisposing factors and development of colostomy prolapse. This study seeks to evaluate the characteristics and life history of colostomy prolapse and to identify possible predisposing factors in our practice. It is hoped that the findings of this study will give surgeons a basis for explanations to parents of children who develop this condition and to know what to expect in terms of progression of this complication.

\section{AIM}

To evaluate the characteristics and occurrence of colostomy prolapse in children and to identify any factors predisposing to this complication in our practice.

\section{PATIENTS AND METHODS}

This is a five year prospective analytic study of all children 15 years and below, who had a colostomy by one of the authors in two public tertiary, and two private health facilities in Rivers State Nigeria between March 2013 and April 2018. Ethical approval was obtained from the institutions' research and ethical committees. Inclusion criteria were colostomy in a child 15 years and below which was carried for a minimum of three months before closure. Exclusion criteria were loss to follow up before closure, older age or refusal to participate. Colostomy prolapse was defined as protrusion of one or both stoma $5 \mathrm{~cm}$ or more beyond the abdominal skin. All colostomies, were followed up to observe any occurrence of prolapse and its timing. The patients were then grouped into two categories; cases of those that developed prolapse (Pro group) and cases of those that did not develop prolapse (Non Pro group). The variables investigated between the two groups were the gender, the age and weight at creation of colostomy, the indication for colostomy, type of colostomy, duration of colostomy, presence 
of raised intra abdominal pressure (chronic cough or straining). The data was subjected to statistical analysis using the SPSS version 21. Test of statistical significance was performed with the student $\mathrm{t}$ test and statistical significance was set at $\mathrm{p}<0.05$.

\section{RESULTS}

A total of 94 children met the inclusion criteria for this study. The duration of colostomy ranged from 6 months to 19 months with a median at 10.2 months. Of these patients, $27(28.4 \%)$ developed colostomy prolapse (Pro group) and 67 (71.6\%) did not (Non Pro group). Earliest occurrence of prolapse was 3 weeks after colostomy while the latest occurrence was at 5 months. The proximal stoma only was involved in $13(48.1 \%$ ) cases; both stomata in $9(33.3 \%)$ cases and the distal stoma only in $5(18.5 \%)$ cases. There were no new occurrences of prolapse after 5 months post colostomy.(Table1)

Twenty two of the prolapse were permanently outside while 5 only became apparent when the patient cried or strained. Of the 22 that were permanently outside, 9 progressively increased in size over the period before closure while 13 stopped enlarging within the first two months of occurrence. The length of prolapsed bowel ranged from 10 to $30 \mathrm{~cm}$. One patient with loop sigmoid colostomy prolapse developed intestinal obstruction requiring emergency take down while two others bled from the prolapsed bowel following minor trauma. There were no cases of chronic cough or excessive straining to micturate or defaecate among the groups. There were therefore no cases of factors causing raised intra abdominal pressure in either group. Between the two groups, there was no significant difference in the gender of the patients, and the duration of the colostomy. However the mean age and mean body weight were significantly higher in the Pro group ( Table 2). Comparing the groups based on the indication, Hirschsprung's disease constituted $55 \%$ of the pro group but $28.4 \%$ of the non pro group. (Table 3). The design and location of colostomy did not affect the occurrence of prolapsed. (Table 4).

Table 1. Timing of occurrence of colostomy prolapse

\begin{tabular}{|l|l|l|}
\hline Time of occurrence of prolapse (Months) & Number of prolapse & Cumulative number of prolapse \\
\hline $0-1$ & 2 & 2 \\
\hline $1-2$ & 4 & 6 \\
\hline $2-3$ & 12 & 18 \\
\hline $3-4$ & 8 & 26 \\
\hline $4-5$ & 1 & 27 \\
\hline $5-12$ & - & 27 \\
\hline $12-24$ & - & 27 \\
\hline
\end{tabular}

Table 2. Comparison of groups gender, age, weight, and colostomy duration

\begin{tabular}{|l|l|l|l|}
\hline \multirow{2}{*}{ Parameter } & \multicolumn{2}{|c|}{ Patient group } & \multirow{2}{*}{ p value } \\
\cline { 2 - 3 } & Pro group(n=27) & Non Pro group(n=67) & \\
\hline Gender (Male: Female) & $\mathrm{M}: \mathrm{F}=15: 10$ & $\mathrm{M}: \mathrm{F}=40: 27$ & $<0.15$ \\
\hline Mean Age at creation of colostomy & $15(\mathrm{SD} \pm 3)$ months & $5.8(\mathrm{SD} \pm 2.2)$ days & $<0.001$ \\
\hline Mean body weight & $9.8 \mathrm{Kg}(\mathrm{SD} \pm 2.6)$ & $6.5 \mathrm{Kg}(\mathrm{SD} \pm 3.1)$ & $<0.05$ \\
\hline Mean duration of colostomy (Months) & $9.2(\mathrm{SD} \pm 3.3)$ & $8.8(\mathrm{SD} \pm 2.2)$ & $<0.1$ \\
\hline
\end{tabular}


Table 3. Comparison of indications among the two groups

\begin{tabular}{|l|l|l|}
\hline \multirow{2}{*}{ Indications for colostomy } & \multicolumn{2}{|c|}{ Patient group $(\mathbf{p}<\mathbf{0 . 0 5})$} \\
\cline { 2 - 3 } & Pro group $(\mathbf{n = 2 7})$ & Non Pro group(n=67) \\
\hline Trauma & $4(14.8 \%)$ & $10(15-0 \%)$ \\
\hline Anorectal malformation & $8(29.6 \%)$ & $32(47.8 \%)$ \\
\hline Hirschsprungs disease & $15(55.6 \%)$ & $19(28.4 \%)$ \\
\hline Cloacal exstrophy & - & $2(3.0 \%)$ \\
\hline Abdominal trauma & - & $2(3.0 \%)$ \\
\hline Colorectal tumour & - & $2(3.0 \%)$ \\
\hline
\end{tabular}

Table 4. Types of colostomy

\begin{tabular}{|l|l|l|l|}
\hline \multirow{2}{*}{$\begin{array}{l}\text { Colostomy Site } \\
\text { (Colon) }\end{array}$} & \multirow{2}{*}{ Design } & \multicolumn{2}{|c|}{ Patient Group } \\
\cline { 3 - 4 } & & Pro group $(\mathbf{n = 2 7})$ & Non Pro group $(\mathbf{n = 6 7 )}$ \\
\hline Ascending & Loop & 1 & 4 \\
\cline { 2 - 4 } & Divided & - & 1 \\
\hline \multirow{3}{*}{ Transverse } & Loop & 4 & 8 \\
\cline { 2 - 4 } & Divided & 3 & 6 \\
\hline \multirow{2}{*}{ Descending } & Loop & - & - \\
\cline { 2 - 4 } & Divided & - & 4 \\
\hline \multirow{2}{*}{ Sigmoid } & Loop & 12 & 31 \\
\cline { 2 - 4 } & Divided & 7 & 13 \\
\hline
\end{tabular}

$\mathrm{P}<0.18$

\section{DISCUSSION}

Prolapse of the colostomy is a common complication in our practice. The incidence in the present series is within the range of $9-45 \%$ reported in other studies. ${ }^{11,12}$ Some authors have reported secondary complications in up to $9 \%$ of cases of colostomy prolapse and 6\% necessitating colostomy revision. ${ }^{12}$ In the present study we managed our cases conservatively till the time we needed to close the colostomy except in one case where intestinal obstruction necessitated emergency colostomy take down. Though there were few secondary complications from the prolapsed colostomy in our series, the size of the prolapsing bowel constituted significant morbidity. Such cases would certainly have benefitted from the laparoscopic enteropexy for prolapsing stoma (LEPS) described by
Davidson et al but for the unavailability of the skills and equipment. ${ }^{13}$ The morbidity of open surgery to correct such progressively enlarging prolapse is the reason surgeons in similar circumstances as ours prefer to manage conservatively. However, surgeons who have the resources for minimally invasive correction like the LEPS and other techniques will tend to explore those options. ${ }^{14}$ This study shows that there is an association of Hirschsprungs disease and prolapse of the colostomy in children. This association tended to be more with increasing age of the patient at the time of colostomy formation. This finding suggests that chronic obstructions with progressive dilatation of the bowel as the child gets older increases the risk of subsequent prolapse if a colostomy is created. This is in line with the findings by other authors who identified chronic intestinal obstruction as 
a potential risk factor. ${ }^{11,15}$ It therefore appears that Hirschsprungs disease presents a specific risk for colostomy prolapse compared to other indications of colostomy in children. It is difficult to explain this finding, but one of the hypothesis we considered is that, the dilated redundant loop of proximal bowel in Hirschsprungs disease may have the tendency to 'fall out' since it has only a minimal restriction by the already stretched mesentery. In younger children who had colostomy early, the less occurrence of prolapse may be due to the fact that the bowel is not as markedly dilated as seen in older children with neglected Hirschsprungs disease. However, Chandramouli et al in another study in India identified no relationship between the primary indication of colostomy and its subsequent prolapse. ${ }^{16}$ Further more, the design or type of colostomy did not have significant association with the occurrence of colostomy prolapse in the present study. This is at variance with the finding in a similar study which reported that loop colostomies were at greater risk of prolapsing than divided colostomies. ${ }^{17,18}$ However, in the review by van den Hondel, almost all the loop colostomies which prolapsed were in the transverse colon whereas almost all the loop colostomies which prolapsed in our series were sited in the sigmoid colon. This therefore brings up the question of whether the discrepancy in the occurrence of loop colostomy prolapse between the two studies was related to the difference in the siting of the stoma. ${ }^{18}$ This question had earlier been interrogated in another study which found that the occurrence of prolapsed did not have association with the site of the stoma. ${ }^{19}$ The involvement of the proximal stoma much more than the distal one corroborates this line of thought. Intra operative efforts have been directed at making the stoma sufficiently tight to prevent the proximal loop of bowel from protruding through while at the same time ensuring that obstruction of the stoma or even strangulation does not occur. The challenge to the surgeon therefore, is balancing the art in fashioning the stoma not to be too wide and not to be too tight. Our result presently shows that colostomy prolapse rate in our colostomy cases is still unacceptably high. We think that an additional effort may be needed to reduce the risk of prolapse particularly in patients with Hirschsprungs disease. Fortunately, the trend in Hirschsprungs disease treatment is towards single stage surgery without need for colostomy. However, in those patients we consider colostomy, we suggest that some stitches attaching the proximal loop to the lateral abdominal wall about $5-10 \mathrm{~cm}$ from the site of the stoma may reduce the incidence of colostomy prolapse in those cases. This idea, however will need to be scientifically tested by a well designed case control study.

\section{CONCLUSION}

Colostomy prolapse is a common complication seen in our paediatric surgery service. Cases of neglected Hirschsprungs disease with markedly dilated large bowel are at the highest risk of this complication. Extra care is therefore needed in creating colostomies in this category of patients to forestall this very distressing morbidity of childhood colostomy. A possible addition to the technique of colostomy to stem the incidence of colostomy prolapse may be to attach the proximal loop to the abdominal wall before siting the colostomy distal to it. This suggestion however requires to be tested scientifically. 


\section{REFERENCES:}

[1] Cataldo P, Mackeigan J. Intestinal stomas: Principles, techniques and management. $2^{\text {nd }}$ ed.; Informa Healthcare Publisher: 2004.

[2] Ameh EA, Dogo PM, Nmadu TN. Emergency neonatal surgery in a developing country. Pediatr Surg Int, 2001; 17 (5-6):448-451.

[3] Brunicardi F C, Andersen D K, Billiar TR, Dunn D L, Hunter J G, Pollock R E. Schwartz's principle of surgery. 9th ed.; The McGraw-Hill Companies: 2011. Medline.

[4] Garofalo T. Colostomy: Types, indications, formation and reversal. In: Fazio VW, Church JM, Wu JS (eds.). Atlas of intestinal stomas, Switzerland; Springer Nature:2018, pp.127-145.

[5] Patwardhan N, Kiely EM, Drake DP, Spitz L, Pierro A. Colostomy for anorectal anomalies: high incidence of complications. J Pediatr Surg. 2001;36(5):795-8.

[6] Jayarajah U, Samarasekara AM, Samarasekera DN. A study of longterm complications associated with enteral ostomy and their contributory factors. BMC Res Notes. 2016;9(1):500.

[7] Ben Ameur H, Affes N, Rejab H, Abid B, Boujelbene S, Mzali R, et al. Surgical complications of colostomies. Tunis Med. 2014 ;92(7):482-7.

[8] Uba AF, Chirdan LB. Colostomy complications in children. Ann Afr Med. 2003; 2(1):9-12.

[9] Ekpemo SC, Eleweke N, Chapp-Jumbo A. Childhood colostomy and its complications in Aba, Nigeria. Int $\mathbf{J}$
Clin Exp Med Sci.2018; 4(3): 32-34. doi:10.11648/j.ijcems. 20180403.11.

[10] Engida A, Ayelign T, Mahteme B, Aida T, Abreham B. Types and indications of colostomy and determinants of outcomes of patients after surgery. Ethiop J Health Sci. 2016; 26(2): 117-120.

[11] Irtan S, Bellaïche M, Brasher C, El Ghoneimi A, Cézard JP, Bonnard A. Stomal prolapse in children with chronic intestinal pseudoobstruction: a frequent complication? J Pediatr Surg. 2010;45(11):2234-7. doi: 10.1016/j.jpedsurg.2010.06.022.

[12] Mullassery D, Lacona R, Cross K, Blackburn S, Kiely E, Eaton S, et al. Loop colostomies are safe in anorectal malformations. J Pediatr Surg. 2018;53(11):2170-2173. doi:10.1016/j.jpedsurg.2018.05.022. Epub 2018 Jun 1.

[13] Davidson J, Healy C, Blackburn SC, Curry J. Laparoscopic enteropexy for prolapsing stoma: A case series describing a novel technique. J Laparoendosc Adv Surg Tech A. 2018;28(9):1135-1138. doi: 10.1089/lap.2017.0730. Epub 2018 Apr 6.

[14] Gundogdu G, Topuz U, Umutoglu T. Laparoscopic correction of right transverse colostomy prolapse. Asian J Endosc Surg. 2013;6(3):220-2. doi: 10.1111/ases.12035.

[15] Ekenze SO, Agugua-Obianyo NEN, Amah CC. Colostomy for large bowel anomalies in children. A case controlled study. Int J Surg. 2007;5:273-277.

[16] Chandramouli B, Srinivasan K, Jagdish S, Ananthakrishnan N. Morbidity and 
Prolapse of colostomy in children; characteristics, predisposing factors and preventive measures in four health facilities in Southern Nigeria

mortality of colostomy and its closure in children. J Pediatr Surg. 2004;39(4):596-9.

[17] Oda O, Davies D, Colapinto K, Gerstle JT. Loop versus divided colostomy for the management of anorectal malformations. J Pediatr Surg. 2014 ;49(1):87-90. doi: 10.1016/j.jpedsurg.2013.09.032. Epub 2013 Oct 8.

[18] van den Hondel D, Sloots C, Meeussen C, Wijnen R. To split or not to split: colostomy complications for anorectal malformations or hirschsprung disease: a single center experience and a systematic review of the literature. Eur J Pediatr Surg. 2014;24(1):61-9. doi: 10.1055/s-0033-1351663. Epub 2013 Aug 5.

[19] Duchesne JC, Wang YZ, Weintraub SL, Boyle M, Hunt JP. Stoma complications: a multivariate analysis. Am Surg. 2002;68(11):961-6.

\section{AUTHOR BIOGRAPHY}

Okoro Philemon E, Paediatric Surgery Unit, Department of Surgery, University of Port Harcourt Teaching Hospital, Port Harcourt, Rivers State Nigeria and Department of Surgery, Madonna University Teaching Hospital, Elele Rivers State, Nigeria and Paediatrics Unit, St Catherine's Specialist Hospital Ltd and Citihome Medical Consultants Ltd, Port Harcourt, Nigeria

Onyesoh Chinyeaka, Paediatrics Unit, St Catherine's Specialist Hospital Ltd 